\title{
Lectures
}

Les comptes rendus

/

2015

\section{Benoît Berthou (dir.), La bande dessinée : quelle lecture, quelle culture?}

\section{BENOÎT CRUCIFIX}

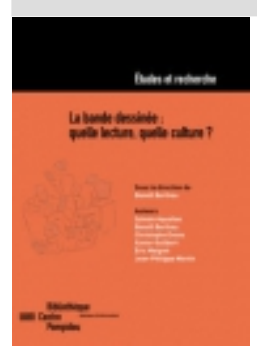

Benoît Berthou (dir.), La Bande dessinée: quelle lecture, quelle culture ?, Éditions de la Bibliothèque publique d'information, coll. «Études et recherche », 2015, ISBN : 9782842462178.

\section{Notes de la rédaction}

Conformément à notre charte déontologique, ce compte-rendu ne traite pas la contribution de Xavier Guilbert, en raison de relations professionnelles avec le rédacteur.

\section{Texte intégral}

PDF

1 À partir d'analyses statistiques, cet ouvrage dirigé par Benoît Berthou, disponible en open access, vient offrir de nouvelles perspectives à un pan de la recherche sur la bande dessinée qui envisage le médium comme une pratique culturelle, et y comble un manque en se penchant sur son lectorat. La lecture de bande dessinée y est examinée dans sa spécificité, sa diversité, ainsi que dans ses rapports à d'autres médias. 
dans un environnement culturel et médiatique foisonnant suit des visées épistémologiques similaires à celles formulées dans La bande dessinée : une médiaculture ${ }^{1}$. Dans cette optique - qui défie l'opposition entre "Culture » consacrée et médias « de masse »-, la bande dessinée est envisagée comme un dispositif culturel en constante mutation, ancré dans ses contextes sociohistoriques et se développant en dialogue avec d'autres médias. Dans Les mangados : lire des mangas à l'adolescence ${ }^{2}$, Christine Détrez et Olivier Vanhée appliquaient déjà une approche similaire à l'étude d'un profil de lecteur spécifique, le « mangado ${ }^{3}$. En partant d'une enquête quantitative plutôt que qualitative, La Bande dessinée : quelle lecture, quelle culture ? entend éclairer cette facette méconnue de la lecture de bande dessinée sur la base de données statistiques, ce qui lui confère une plus grande envergure. L'étude repose sur une large enquête, commandée par le département des études, de la prospective et des statistiques du ministère de la Culture et la Bibliothèque Publique d'Information, et réalisée avec l'aide du LABoratoire des Sciences de l'Information et de la Communication de l'université Paris 13, du LABEX Industries Culturelles \& Création Artistique et de la Cité Internationale de la Bande Dessinée et de l'Image.

L'introduction de Benoît Berthou et Jean-Philippe Martin présente l'historique du projet, la méthodologie employée, et les objectifs poursuivis dans le reste du livre. Les auteurs situent la lecture de bande dessinée dans une perspective historique, montrant comment celle-ci continue à nous poser un défi par son statut ou son invisibilité : en témoigne sa place " inavouable » et/ou « négligeable » (§ 15) au sein de l'enquête Pratiques culturelles des Français, qui n'intégrera véritablement la bande dessinée dans son questionnaire qu'en 2008. Dans un tel contexte, le présent ouvrage répond donc à une nécessité cruciale, se penchant sur une lecture souvent négligée ou mal comprise.

Christophe Evans, sociologue de la lecture, se concentre sur une première facette de ce lectorat en en analysant les différents profils selon les variables socio-démographiques traditionnelles (âge, sexe, niveau de diplôme, profession). Présentés avec nuance et précaution, les résultats nous invitent à revenir sur un certain nombre de lieux communs, surtout par rapport à l'âge et au sexe de ses lecteurs. En effet, suite à l'extension de la bande dessinée en termes de visibilité, d'offre et de reconnaissance, on a assisté à un discours récurrent dans les médias et la critique, postulant que ce lectorat se serait d'une part fortement féminisé et aurait d'autre part vieilli. Au contraire, Evans constate que « la féminisation du lectorat de la bande dessinée n'a pas eu lieu » (I § 16), l'écart entre lectorat masculin et féminin ne s'étant pas réduit. Quant à l'âge, si la lecture de bande dessinée est fort présente chez les adultes, elle reste ancrée dans la culture juvénile, avec un attrait particulier et un attachement fort chez les pré-adolescents. Au-delà de ces variables, l'enquête met également en exergue l'extrême diversité et hétérogénéité des pratiques : en grande majorité, la lecture de bande dessinée se range non seulement à côté d'autres types de lectures, mais concerne également plusieurs genres au sein du médium. Les catégories d'âge font toutefois émerger des " parts de lecture » sensiblement différentes, inscrites dans une trajectoire générationnelle : l'album traditionnel est fort représenté au-delà de quarante ans, en dessous de quoi le manga, le roman graphique et les comics occupent de plus larges portions.

Expert en culture juvénile, Sylvain Aquatias pose la question du goût pour la bande dessinée : la façon dont celui-ci s'acquiert, se transmet, se perd ou se renforce. Dans la continuité des résultats d'Evans, Aquatias réitère l'importance de la lecture de bande dessinée pendant l'enfance. Il apparait que la transmission familiale - surtout quand les parents sont eux-mêmes fervents lecteurs - joue un 
rôle important, mais non exclusif, dans l'acquisition du goût pour la bande dessinée, qui peut également se faire via des déclinaisons transmédias, la bibliothèque et/ou les pairs. Ces derniers points restent cependant des zones d'ombre dans l'enquête réalisée et leur impact gagnerait donc à être analysé plus en profondeur. Se pose également la question du (non-)développement du goût, l'arrêt de la lecture de bandes dessinées se faisant surtout à l'adolescence, moment-charnière où redistribution du temps et perception de la bande dessinée participent à cet abandon. Dans le prolongement de l'hétérogénéité susmentionnée, les lecteurs multi-genres sont donc ceux chez qui le goût de la bande dessinée va se renforcer davantage, alors que les lecteurs exclusifs sont les premiers à abandonner. Des effets de légitimité viennent toutefois caractériser certains genres - le manga, les comics et le roman graphique - en fonction du niveau de diplôme, faisant apparaître des comportements plus sélectifs que pendant l'enfance.

6 Dans sa contribution, Éric Maigret ajoute un volet statistique à sa réflexion antérieure sur la légitimité de la bande dessinée 4 . On observe tout d'abord une reconnaissance généralisée de la bande dessinée comme « un art à part entière », manifestant « un devoir multiculturel de ne pas manifester une intolérance à l'égard des goûts des autres » (IV § 3). Maigret perçoit néanmoins des effets d'âge, témoignant de l'arrivée de nouvelles générations chez qui priment le divertissement et pour qui la légitimité culturelle est acquise, là où les générations antérieures adoptent un ton militant pour la reconnaissance symbolique de la bande dessinée. Si les variables d'âge semblent primer sur celles de classe, Maigret révèle certains effets distinctifs liés à l'appropriation de la bande dessinée par les milieux supérieurs, mais ceux-ci présentent néanmoins une extrême hétérogénéité de goûts caractéristique d'un public « omnivore ${ }^{5}$. Avec cette montée du divertissement, la bande dessinée prend donc part à une transition vers un régime "postlégitime ", ce qui remet en question le principe de distinction culturelle et vient enrichir les arguments de sociologues comme Hervé Glevarec.

7 Les deux derniers chapitres, signés par Benoît Berthou, se concentrent respectivement sur les pratiques de médiation et sur la bande dessinée comme culture graphique. Le premier vient montrer un manque de médiateurs pour la bande dessinée en général, présentant un lecteur qui « se débrouille seul » $(\mathrm{V} \S$ 3). Largement partagée, cette condition de lecture, tout à fait originale, revendique la capacité à opérer un choix sans l'appui de médiateurs tels que les libraires et bibliothécaires. Ce cas révèle la collection comme une autre forme de médiation, fournissant un espace d'autonomie revendiquée par un lecteur qui se soustrait aux formes explicites de conseil. Berthou décrit ensuite la connexion entre intensité de lecture, réflexivité, et volonté de partage, formant une sociabilité qui se traduit par une forte implication dans des sites, forums, et autres plateformes numériques et par une participation à des rencontres et événements (festivals, cosplays). Ces événements proposent en outre un lieu de rencontre entre auteurs et lecteurs, dévoilant un large intérêt pour l'auteur à travers les différents genres : cette pratique fait la part belle à la création, défiant la présumée insignifiance du créateur dans les « industries culturelles » telles qu'elles ont été pensées par une tradition critique qui remonte à Adorno et Horkheimer.

8 Sur cette importance de la création, Benoît Berthou conclut l'ouvrage avec une réflexion sur la place de la bande dessinée dans la culture de l'image. Il montre tout d'abord que la lecture de bande dessinée se range à côté d'autres pratiques culturelles liées à l'image, réaffirmant la corrélation entre diversité et intensité suggérée par Aquatias et manifestant d'une « logique de cumul ». L'idée de 
« cumul » vient illuminer les échanges entre divers pratiques du « visuel »écrans, imprimé et produits dérivés - et la bande dessinée apparaît comme un livre qui «bourgeonne »(VI $\S 26)$, qui invite à d'autres intérêts et loisirs, poussant ainsi ses propres frontières définitionnelles. Dans ce contexte, le média s'inscrit dans une logique de « transfictionalité », c'est-à-dire la reprise d'éléments fictifs à travers plusieurs textes et médias, tout en invitant à repenser ce concept. Constatant l'attrait avoué des lecteurs pour le dessin, Berthou avance avec brio que dessin et style forment des critères esthétiques qui prennent le pas sur le rôle structurant du personnage dans la transfiction. Ces critères se traduisent ensuite dans les pratiques d'amateur des lecteurs, qui souvent prennent à leur tour le crayon. Pour les lecteurs de bande dessinée, " histoire et dessin vont de pair » (VI $\S 43$ ), illuminant une forme de narration liée à son mode de création.

Dans son ensemble, La bande dessinée : quelle lecture, quelle culture ? n'analyse pas seulement de façon rigoureuse et nuancée des données originales, jetant un regard complet sur la lecture de bande dessinée comme pratique culturelle, mais montre aussi comment son étude nous invite à repenser certaines des catégories et concepts traditionnels utilisés pour caractériser la culture du livre, de l'imprimé, et de l'image.

\section{Notes}

1 Maigret Éric et Stefanelli Matteo (dir.), La bande dessinée : une médiaculture, Paris, Armand Colin, coll. « Médiacultures », 2012.

2 Détrez, Christine, and Olivier Vanhée. Les mangados : Lire des mangas à l'adolescence. Paris, Éditions de la Bibliothèque publique d'information, coll. " Études et Recherche », 2012.

3 Bien que les auteurs de l'ouvrage en question ne s'y référent que rarement, on peut également noter un intérêt similaire dans la variante anglo-saxonne des comics studies, où des chercheurs tels que Mel Gibson ou Jared Gardner se sont intéressés au lecteur de bande dessinée sous différents aspects. Voir Gibson Mel, « What You Read and Where You Read It, How You Get It, How You Keep It: Children, Comics and Historical Cultural Practice ", Popular Narrative Media, vol. $1 \mathrm{n}^{\circ}$ 2, 2008, p. 151-167. Weiner Robert G., Gibson Mel (dir.), « Audiences and Readership », Journal of Graphic Novels and Comics, vol. $2 \mathrm{n}^{\circ}$ 2, 2011. Gardner Jared, Projections. Comics and the History of Twenty-FirstCentury Storytelling, Palo Alto, Stanford University Press, coll. « Post 45 », 2012.

$4 C f$. Maigret Éric, "La reconnaissance en demi-teinte de la bande dessinée ", Réseaux, vol. $12 \mathrm{n}^{\circ}$ 67, 1994, pp. 113-140. Maigret Éric. « Bande dessinée et postlégitimité. », in Éric Maigret et Matteo Stefanelli (dir.), La bande dessinée : une médiaculture, Paris, Armand Colin, coll. « Médiacultures », 2012, p. 130-148.

5 Sur la notion d'« omnivorité », voir Peterson Richard, "Understanding Audience Segmentation. From Elite and Mass to Omnivore and Univore », Poetics, $n^{\circ} 21,1992$, p. 243-258.

\section{Pour citer cet article}

Référence électronique

Benoît Crucifix, « Benoît Berthou (dir.), La bande dessinée : quelle lecture, quelle

culture? », Lectures [En ligne], Les comptes rendus, 2015, mis en ligne le 23 mars 2015, consulté le 27 avril 2015. URL : http://lectures.revues.org/17451

\section{Rédacteur}

Benoît Crucifix

Diplômé de Master en langues et littératures modernes de l'Université catholique de 
Louvain, étudiant de Master spécialisé en études littéraires à la KU Leuven

\section{Droits d'auteur}

(C) Lectures - Toute reproduction interdite sans autorisation explicite de la rédaction / Any replication is submitted to the authorization of the editors 